\title{
Swimming and escape behavior of copepod nauplii: implications for predator-prey interactions among copepods
}

\author{
Josefin Titelman* \\ Danish Institute for Fisheries Research, Department of Marine and Coastal Ecology, Kavalergården 6, \\ 2920 Charlottenlund, Denmark
}

\begin{abstract}
This study focuses on how prey behavior may affect predation risk through encounter rates and the escape success of the prey given an encounter. Temora longicornis nauplii require stronger hydrodynamic signals to elicit escape than Acartia tonsa nauplii (critical fluid deformation rates, $\Delta^{*}$ of 2.8 to 4.0 and 1.2 to $2.5 \mathrm{~s}^{-1}$, respectively) suggesting that $T$. longicornis may be more susceptible to predation. Quantification of naupliar motility behavior and subsequent estimation of the hydrodynamic signals which the nauplii generate suggest that an adult female Centropages typicus may detect an $A$. tonsa nauplius at a greater distance than a similarly sized $T$. longicornis nauplius. Observations of attacks of free swimming $C$. typicus and the naupliar prey confirmed that $T$. longicornis is poorer at detecting predators than A. tonsa, and that the same predator detects $A$. tonsa at a greater distance than it detects $T$. longicornis nauplii $(2.37 \pm 1.46$ and $0.34 \pm 0.18 \mathrm{~mm}$, respectively). The combined effect of prey motility and escape behavior was tested by offering $C$. typicus females the 2 prey species alone and in mixtures. Clearance rates on T. longicornis $\left(442 \pm 125 \mathrm{ml}^{-1} \mathrm{~d}^{-1}\right)$ were ca 3 -fold that on $A$. tonsa nauplii $\left(146 \pm 35 \mathrm{ml} \mathrm{o}^{-1} \mathrm{~d}^{-1}\right)$ in both single species and mixed treatments. While the low profile motility behavior of $T$. longicornis appears to reduce encounter rates, its post encounter (i.e., escape) behavior is less effective. In contrast, the behavior of $A$. tonsa acts predominantly at the post-encounter stage where its sensitivity to hydrodynamic signals (i.e., low $\Delta^{*}$ ) effectively compensates for the high predator encounter rate generated by its motility.
\end{abstract}

KEY WORDS: Acartia tonsa - Temora longicornis - Centropages typicus - Behavior - Escape · Predation · Nauplii

Resale or republication not permitted without written consent of the publisher

\section{INTRODUCTION}

Predation risk is the likelihood of being eaten during some time period. This definition includes the 3 main components of predation risk: (1) the encounter rate between predator and prey, (2) the probability of death given an encounter, and (3) the time spent vulnerable to attack (Lima \& Dill 1990). Attack, capture and ingestion may follow an encounter, and their relative outcome determines the probability of death (Ohman

*E-mail: jti@dfu.min.dk
1988, Lima \& Dill 1990). Both predator and prey behavior can affect predation risk through enhancing or limiting encounter rates and the success of the subsequent events (Ohman 1988).

Copepods perceive fluid disturbances by means of mechanoreception (Haury et al. 1980, Landry 1980, Légier-Visser et al. 1986, Yen et al. 1992). This sensory ability allows for the detection of potential prey (Kerfoot 1978, Landry 1978, Svensen \& Kiørboe 2000) predators (Yen \& Fields 1992, Viitasalo et al. 1998) and may help parasitic copepods to locate hosts (Heuch \& Karlsen 1997). Kiørboe et al. (1999) separated the components of a fluid disturbance and observed the behav- 
ior of a copepod. Their analysis suggested that small prey perceive the fluid deformation generated by a larger predator, while a large predator perceives the fluid velocity generated by small prey (Kiørboe \& Visser 1999, Kiørboe et al. 1999).

The magnitude of a hydrodynamic signal can be estimated from an organism's motility pattern and size (Tiselius \& Jonsson 1990, Tiselius et al. 1997, Kiørboe \& Visser 1999, Svensen \& Kiørboe 2000). The behavioral component of encounter rate is $\pi R^{2} V$, where $R$ is the sum of the predator's perceptive distance and the prey size (i.e., radius), and $v$ is the relative velocity difference between predator and prey (Kiørboe \& Saiz 1995). Given that zooplankton behavior generates hydrodynamic signals, it is reasonable to hypothesize that differences in prey behavior may translate into differences in predation (Paffenhöfer et al. 1996) by affecting encounter rates through both $R$ and $v$ (Tiselius et al. 1997)

Once encountered, many zooplankton prey including copepods use rapid jumps to escape their predators (Ohman 1988). The characteristics of the induction of escape response have been investigated using moving objects (Haury et al. 1980, Wong 1996), in siphon setups, where animals are exposed to a symmetric flowfield (Singarajah 1969, Buskey 1994, Fields \& Yen 1997a, Viitasalo \& Rautio 1998, Kiørboe et al. 1999), and with tethered filtering predators (Yen \& Fields 1992, Fields \& Yen 1997b). Given that prey have different perceptive and escape abilities, one may also hypothesize that predation rates reflect differences in these behaviors (Viitasalo \& Rautio 1998, Viitasalo et al. 1998).

This study focuses on how prey behavior may affect predation risk through both (1) encounter rates, and (2) the escape success of the prey given an encounter. I consider perceptive abilities, motility and escape behaviors of nauplii of two different copepod species (Acartia tonsa and Temora longicornis) in conjunction with data on predation by a larger copepod predator (Centropages typicus). By attempting to separate the predation process into its components, the aim of this paper is to see how and where prey behavior is important in zooplankton predator-prey interactions.

\section{METHODS}

Zooplankton cultures. The Acartia tonsa used in the experiments came from our laboratory culture (Støttrup et al. 1986). Temora longicornis were collected in Øresund, Denmark, in November 1998 and in July 1999, and were similarly kept in a continuous culture for egg laying purposes. Copepods were reared in 30 to 2001 containers and fed a mixture of Rhodomonas baltica $(\mathrm{ESD}=7 \mu \mathrm{m})$ and Thalassiosira weissflogii $(\mathrm{ESD}=12 \mu \mathrm{m})$ ad libitum. Cohorts of copepods were obtained by allowing eggs to hatch for ca $12 \mathrm{~h}$, after which unhatched eggs were removed. Unless otherwise noted, all experiments and zooplankton culturing were carried out at $30 \mathrm{psu}$, room temperature and ambient light regimes.

Pipette experiments. To assess the perceptive ability of Temora longicornis and to look closer at the characteristics of the escape events, a series of suction siphon experiments were conducted. By exposing the copepods to the flow field created by the siphon, and by noting the distance from the siphon at which the copepod responds to the flow it is possible to quantify the critical fluid deformation rate needed to induce an escape response. Critical deformation rates required to induce response in Acartia tonsa were taken from Kiørboe et al. (1999).

Set-up: Kiørboe et al. (1999) describe the set-up and associated theory in detail. Briefly, the set-up consists of an aquarium $(25 \mathrm{~cm} \times 25 \mathrm{~cm} \times 50 \mathrm{~cm})$ with a Pasteur pipette $(\varnothing=1.1 \mathrm{~mm})$ mounted in the bottom through which a gravity-driven flow passes. The attempted flow rate was $2.1 \mathrm{ml} \mathrm{s}^{-1}$. Experiments were filmed using a 3D set-up with 2 CCD cameras (Minitron MTV1802CD) equipped with macro lenses (Nikkor AF Micro $105 \mathrm{~mm}$ ) connected to a synchronizer, a mixer, a time-date generator (Panasonic WJ 180) and a VCR (Panasonic NV-FS200 HQ). Experiments were carried out at $16^{\circ} \mathrm{C}$, using collimated light from 2 IR diodes as the only light source for filming. The concentration of copepods ranged from 30 to $300 \mathrm{l}^{-1}$. The magnifications were optimized for a maximum field of view, and were thus dependent on the size of the copepods. Table 1 summarizes the copepod size distributions and flow conditions for each experiment.

Image analysis: Videos were analyzed frame by frame for start and end points of escape jumps. In the cases where the copepods managed to escape but got caught in the flow again, only the first reaction was recorded. Only jumps initiated above the mouth of the pipette and with flow corrected jump lengths exceeding 1 body length were considered in the final analyses. The critical deformation rate required to induce a response $\left(\Delta^{*}\right)$ was calculated from the start point of the jump as (Kiørboe et al. 1999)

$$
\Delta^{*}=\frac{Q}{2 \pi r^{3}}
$$

where $Q$ is the volume flow rate and $r$ the distance from the mouth of the siphon where the copepod initiates its escape. The critical signal strength due to deformation $\left(s_{\Delta^{*}}\right)$ is (Kiørboe et al. 1999)

$$
S_{\Delta^{*}}=\Delta^{*} \times r_{\text {prey }}
$$


Table 1. Temora longicornis. Summary of pipette experiments. The stage column shows the 2 most common stages (n = 30), with the most abundant stage underlined and the percentage contribution of the 2 dominant stages in parentheses. Lengths are total lengths excluding caudal armature for nauplii, and prosome lengths for copepodids. Flow rates $(Q)$ are integrated over the entire course of the experiment. In all subsequent analyses, data were pooled according to the first column

\begin{tabular}{|c|c|c|c|c|c|c|}
\hline Pooled group & $\begin{array}{c}\text { Expt } \\
\text { (Pipette no.) }\end{array}$ & $\begin{array}{c}\text { Stage } \\
(\%)\end{array}$ & $\begin{array}{l}\text { Age } \\
\text { (h) }\end{array}$ & $\begin{array}{c}\text { Length } \pm \text { SD } \\
(\mu \mathrm{m})\end{array}$ & $\mathrm{n}$ & $\begin{array}{c}Q \\
\left(\mathrm{ml} \mathrm{s}^{-1}\right)\end{array}$ \\
\hline NII-NIII & $\begin{array}{l}1 \\
2 \\
3 \\
4\end{array}$ & $\begin{array}{l}\text { NI-NII (100) } \\
\text { NII-NIII (87) } \\
\text { NII-NIII (89) } \\
\text { NII-NIII (93) }\end{array}$ & $\begin{array}{l}44-56 \\
49-61 \\
72-84 \\
84-96\end{array}$ & $\begin{array}{l}147 \pm 20 \\
171 \pm 25 \\
186 \pm 21 \\
178 \pm 23\end{array}$ & $\begin{array}{l}92 \\
25 \\
19 \\
65\end{array}$ & $\begin{array}{l}2.30 \\
2.29 \\
2.30 \\
2.31\end{array}$ \\
\hline NIII-NIV & $5^{\mathrm{a}}$ & NIII-NIV (80) & $109-121$ & $237 \pm 27$ & 91 & $1.99 / 2.31$ \\
\hline NV-NIV & $\begin{array}{l}6 \\
7\end{array}$ & $\begin{array}{l}\text { NV-NVI (70) } \\
\underline{N V}-N V I(90)\end{array}$ & $\begin{array}{l}134-146 \\
169-181\end{array}$ & $\begin{array}{l}286 \pm 45 \\
304 \pm 39\end{array}$ & $\begin{array}{l}31 \\
34\end{array}$ & $\begin{array}{l}2.29 \\
2.35\end{array}$ \\
\hline $\mathrm{CI}-\mathrm{CII}$ & $\begin{array}{l}8^{\mathrm{a}} \\
9^{\mathrm{a}}\end{array}$ & $\begin{array}{r}\underline{\mathrm{CI}}(100) \\
\underline{\mathrm{CI}}-\mathrm{CII}(100)\end{array}$ & $\begin{array}{l}192-204 \\
215-227\end{array}$ & $\begin{array}{l}336 \pm 13 \\
345 \pm 28\end{array}$ & $\begin{array}{c}45 \\
16 / 59^{\mathrm{b}}\end{array}$ & $\begin{array}{c}1.95 / 2.27 \\
2.27\end{array}$ \\
\hline CIII-CIV & $\begin{array}{l}10 \\
11\end{array}$ & $\begin{array}{l}\text { CII-CIII (90) } \\
\text { CIV-CV (60) }\end{array}$ & $\begin{array}{l}245-258 \\
288-300\end{array}$ & $\begin{array}{l}423 \pm 37 \\
546 \pm 87\end{array}$ & $\begin{array}{l}16 \\
23\end{array}$ & $\begin{array}{l}2.26 \\
2.32\end{array}$ \\
\hline
\end{tabular}

where $r_{\text {prey }}$ is the radius of the prey, here approximated as half the body length.

Distances, directions and velocities of escape jumps were calculated from start and end positions of the jumps. Because the siphon flow distorts jump distances, these calculations were made using flow-corrected end points of the jumps. The equations used for the flow correction and the calculation of the jump angle relative to a flow line are given in Jakobsen (2001). Briefly, the flow correction consists of (1) a coordinate transformation of 3D coordinates into 2D coordinates, (2) the actual flow correction, and (3) a subsequent back transformation of the flow corrected coordinates.

Jump directionality: Directions of flow-corrected escape jumps were expressed relative to flow direction and relative to the horizontal (gravity) in Temora longicornis nauplii and copepodids. Because of the radial symmetry of the flow, all jump angles relative to the flow direction fall between 0 and $180^{\circ}$, where angles $<90^{\circ}$ are against the flow direction and angles $>90^{\circ}$ are with the flow direction. Likewise, escape angles relative to the horizontal vary between $-90^{\circ}$ and $+90^{\circ}$, where $-90^{\circ}$ corresponds to jumping straight downwards and $+90^{\circ}$ to jumping straight up.

I examined whether the copepods directed their escape jumps in response to the direction of the flow. From the distributions of escape directions relative to the horizontal, one can predict the expected distribution of jump angles relative to the flow line had there been no impact of the flow on the directionality (Fig. 1A-C). Because the expected distribution relative to the flow line depends on the angle of the flow line relative to the horizontal ( $\alpha$, which varies between 0 and $90^{\circ}$ for flow lines above the mouth of the pipette) the data were divided into groups of $\alpha=0$ to $30^{\circ}, \alpha=30$ to $60^{\circ}$, and $\alpha=60$ to $90^{\circ}$. The expected distributions relative to flow lines at $\alpha=15^{\circ}, \alpha=45^{\circ}$ and $\alpha=75^{\circ}$ were then calculated (cf. Fig. 1A-C). The observed distributions of jump angles relative to the flow of the 3 groups $\left(\alpha_{0-30^{\circ}}, \alpha_{30-60^{\circ}}\right.$ and $\left.\alpha_{60-90^{\circ}}\right)$ were then compared with the expected distributions of their respective representative flow lines $\left(\alpha_{15^{\circ}}, \alpha_{45^{\circ}}\right.$ and $\left.\alpha_{75^{\circ}}\right)$ using a $G$-test for goodness of fit following Sokal \& Rohlf (1995).

Predation experiments. A series of experiments in which Centropages typicus females were feeding on late nauplii (NIV-NVI) of Temora longicornis and Acartia tonsa were conducted. These stages were chosen, because in these stages the 2 species show the largest difference in the critical deformation rates required to induce escape response $\left(\Delta^{*}\right)$ (Fig. 2).

Centropages typicus were collected in Gullmarsfjorden, on the west coast of Sweden, with a $200 \mu \mathrm{m}$ mesh size net. The animals were acclimatized in the laboratory for 24 to $48 \mathrm{~h}$ prior to each experiment, of which the last 10 to $14 \mathrm{~h}$ were in $0.5 \mu \mathrm{m}$ filtered seawater. Nauplii were individually added to $1160 \mathrm{ml}$ bottles filled with filtered seawater, after which 3 female C. typicus were added to each bottle. Bottles were then sealed and incubated overnight (12 to $18 \mathrm{~h})$ on a slowly rotating plankton wheel $(0.2 \mathrm{rpm})$. At the end of the experiments, bottle contents were filtered on a $50 \mu \mathrm{m}$ mesh and preserved in Lugol's for subsequent enumeration. Animals were staged and sized at the beginning and end of each experiment (Table 2). 


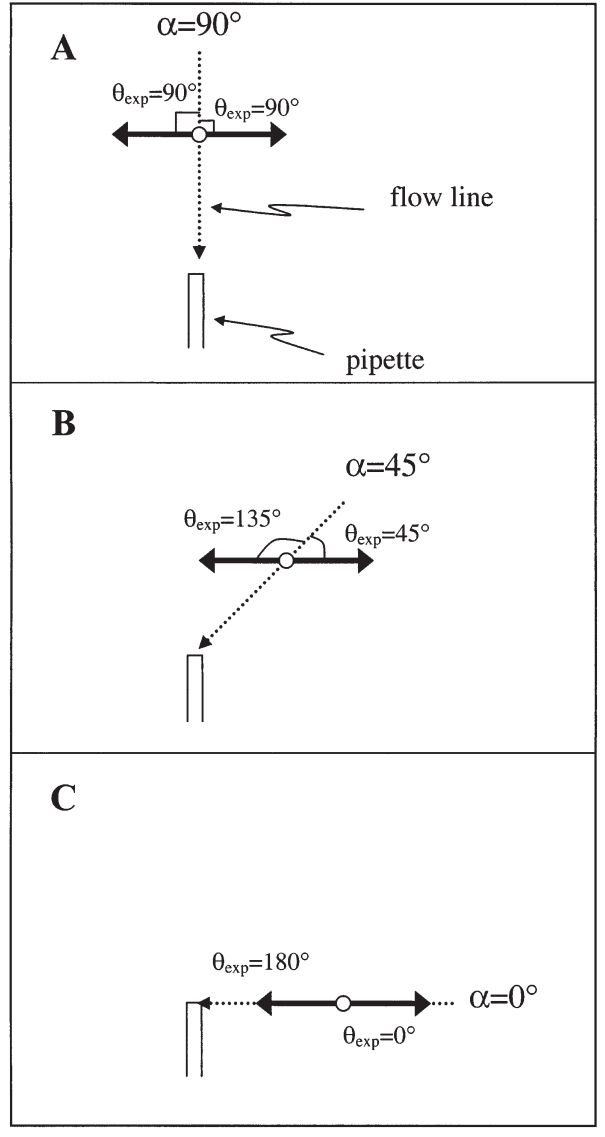

Fig. 1. A simple example explaining how the expected jump angles relative to the flow lines $\left(\theta_{\text {exp }}\right)$ are estimated. Consider a hypothetical case where all nauplii jump horizontally $\left(0^{\circ}\right)$. The bold arrows represent this hypothetical distribution and the white circles represent the start point of the jumps. If there is no impact of the flow on the jump directionality, $\theta_{\exp }$ would depend only on the angle of the flow line relative to a horizontal plane ( $\alpha$ ). (A) At $\alpha=90^{\circ}$ the expected jump angle relative to the flow line is $\theta_{\exp }=90^{\circ}$. (B) At $\alpha=45^{\circ}$, the expected distribution is equally divided between $\theta_{\exp }=$ $45^{\circ}$ and $\theta_{\exp }=135^{\circ}$. (C) At $\alpha=0^{\circ}$ the expected distribution is equally divided between $\theta_{\exp }=0^{\circ}$ and $\theta_{\exp }=180^{\circ}$

I estimated the error associated with pipetting and sieving nauplii from control bottles without predators. Ingestion rates $\left(I\right.$, no. $\left.o^{-1} \mathrm{~d}^{-1}\right)$ and clearance rates $(F, \mathrm{ml}$

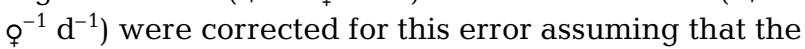
main error was introduced when setting up the experiment and thus calculated as:

and

$$
I=\frac{n_{\text {preystart }}-n_{\text {preyend }}-\text { error }}{n_{\text {pred }} \times\left(\frac{\Delta t}{24}\right)}
$$

$$
F=\frac{\left[\ln \left(n_{\text {preystart }}-\text { error }\right)-\ln n_{\text {preyend }}\right] \times V}{n_{\text {pred }} \times\left(\frac{\Delta t}{24}\right)}
$$

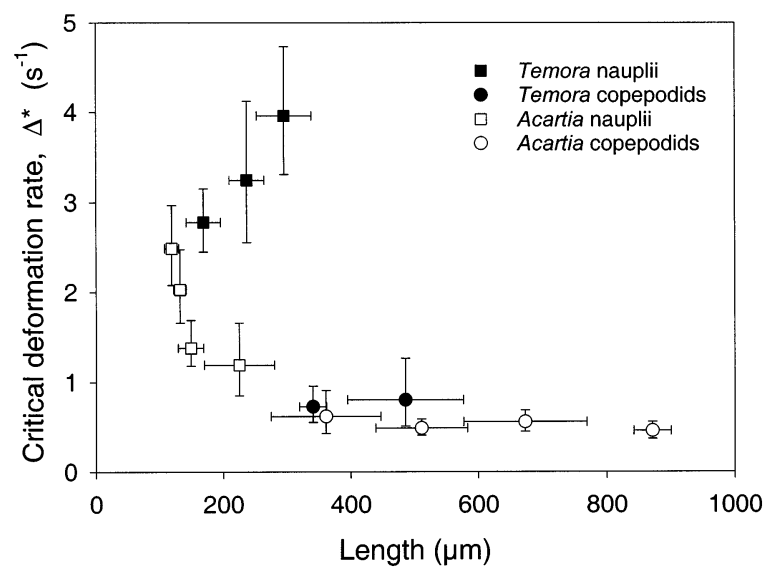

Fig. 2. Critical fluid deformation rates $\left(\Delta^{*}\right)$ required to elicit escape response in Temora longicornis and Acartia tonsa. Data for $\Delta^{*}$ are geometric means with error bars representing confidence interval. Body lengths correspond to total lengths (excluding caudal armature) for nauplii and prosome lengths for copepodids, and are arithmetic means $\pm \mathrm{SD}$. Data for $A$. tonsa come from Kiørboe et al. (1999). See Table 1 for T. longicornis stage distributions

respectively, where $n_{\text {preystart }}$ and $n_{\text {preyend }}$ are the number of prey at the beginning and end of the experiment, $n_{\text {pred }}$ is the number of predators, $\Delta t$ is the incubation time (h), and $V$ is the bottle volume.

Functional response: To ensure that the subsequent experiments were carried out in the linear part of the functional response (FR) curve, 3 independent initial experiments were conducted. In each experiment prey were offered at initial concentrations of 10, 20,40, 80, and 160 nauplii bottle ${ }^{-1}(1160 \mathrm{ml})$. The set-up was always 5 replicates per prey concentration and 4 to 5 control bottles without predators at 2 different prey concentrations. Two experiments were conducted with Acartia tonsa as prey and 1 experiment with Temora longicornis as prey. The experiment with $A$. tonsa was repeated because many of the nauplii molted into $\mathrm{C} 1$ during the course of the first experiment (Table 2, FR 1). The highest prey concentration in the first $A$. tonsa experiment was 80 nauplii bottle $\mathrm{e}^{-1}$, and the highest (160 nauplii bottle ${ }^{-1}$ ) concentration in the T. longicornis experiment had 2 replicates only.

Single and mixed species experiments: Four independent experiments in which the 2 prey species were offered alone and in mixtures were then conducted. The set-up was 5 to 7 replicate bottles of each Temora longicornis, Acartia tonsa, mixed species, and mixed controls without predators, at initial concentrations of 60 nauplii bottle $\mathrm{e}^{-1}(1160 \mathrm{ml})$ for single species treatments, and $30+30$ nauplii bottle ${ }^{-1}$ for mixed treatments. In the first experiment (Single/mix 1), the Centropages typicus were in bad condition, but the experiment was carried out despite this. The results 
Table 2. Acartia tonsa and Temora longicornis. Stage and size distributions at start and end of predation experiments. FR: functional response. See Table 1 for explanation

\begin{tabular}{|c|c|c|c|c|c|}
\hline \multirow[t]{2}{*}{ Expt } & \multirow{2}{*}{ Prey species } & \multicolumn{2}{|c|}{ Start } & \multicolumn{2}{|r|}{ End } \\
\hline & & Stages $(\%)$ & Length $\pm \mathrm{SD}(\mu \mathrm{m})$ & Stages $(\%)$ & Length $\pm \mathrm{SD}(\mu \mathrm{m})$ \\
\hline FR 1 & A. tonsa & $\underline{\text { NV-NVI (84) }}$ & $234 \pm 26$ & NVI-CI (90) & $300 \pm 42$ \\
\hline FR 2 & A. tonsa & NV-NVI (77) & $228 \pm 22$ & NV-NVI (73) & $246 \pm 30$ \\
\hline FR 3 & T. longicornis & NIV-NV (90) & $240 \pm 22$ & NIV-NV (73) & $247 \pm 31$ \\
\hline Single/mix 1 & $\begin{array}{l}\text { A. tonsa } \\
\text { T. longicornis }\end{array}$ & $\begin{array}{l}\text { NIV-NV (90) } \\
\text { NIV-NV (90) }\end{array}$ & $\begin{array}{l}204 \pm 18 \\
253 \pm 24\end{array}$ & $\begin{array}{l}\text { NIV-NV }(87) \\
\text { NV-NVI }(70)\end{array}$ & $\begin{array}{l}204 \pm 22 \\
267 \pm 33\end{array}$ \\
\hline Single/mix 2 & $\begin{array}{l}\text { A. tonsa } \\
\text { T. longicornis }\end{array}$ & $\begin{array}{l}\mathrm{NV}-\mathrm{NVI}(83) \\
\underline{\mathrm{NV}}-\mathrm{NVI}(93)\end{array}$ & $\begin{array}{l}207 \pm 16 \\
294 \pm 44\end{array}$ & $\begin{array}{l}\text { NIV-NV (83) } \\
\text { NV-NIV (90) }\end{array}$ & $\begin{array}{l}207 \pm 15 \\
307 \pm 30\end{array}$ \\
\hline Single/mix 3 & $\begin{array}{l}\text { A. tonsa } \\
\text { T. longicornis }\end{array}$ & $\begin{array}{l}\text { NV-NVI (93) } \\
\text { NV-NVI (87) }\end{array}$ & $\begin{array}{l}249 \pm 20 \\
280 \pm 24\end{array}$ & $\begin{array}{l}\text { NVI-C1 }(80) \\
\text { NV-NVI }(100)\end{array}$ & $\begin{array}{l}264 \pm 40 \\
298 \pm 26\end{array}$ \\
\hline Single/mix 4 & $\begin{array}{l}\text { A. tonsa } \\
\text { T. longicornis }\end{array}$ & $\begin{array}{l}\text { NIV-NV (90) } \\
\text { NIV-NV (87) }\end{array}$ & $\begin{array}{l}203 \pm 18 \\
244 \pm 29\end{array}$ & $\begin{array}{l}\text { NIV-NV (90) } \\
\text { NIV-NV (87) }\end{array}$ & $\begin{array}{l}225 \pm 15 \\
258 \pm 34\end{array}$ \\
\hline
\end{tabular}

were tested using an ANOVA on square root transformed clearance rates from all 4 experiments combined, with prey species and prey mixture as fixed factors (each with 2 levels). The transformation was made to meet the assumptions of normality and homogeneity of variance, which were tested with KolmogorovSmirnov and Levene's tests, respectively.

Filming of behavior. The behavior of Temora longicornis and Acartia tonsa nauplii was determined from 2D (i.e., 1 camera) video recordings with and without a Centropages typicus predator. Infrared diodes provided the only light source during filming. The nauplii were filmed in $62.5 \mathrm{ml}$ Nunclon bottles at concentrations of 40 to 100 per bottle. The field of view in the films was ca $2.6 \times 3.8 \mathrm{~cm}$.

General behavior: The nauplii in the recordings without a predator were analyzed frame by frame using an automated system for tracking and digitizing (Labtrack $\mathrm{QT}^{\odot}{ }^{\odot}$ software, developed in LabVIEW 5.0 by Nick Blackburn). Randomly selected video sequences were analyzed for each of the 2 prey species. Swimming, jumping and sinking velocities and the relative time spent in these behaviors were calculated considering a minimum of 9 tracks per species. Samples were preserved for size and stage determination.

Behavior during predator and prey encounters: The attack behavior of Centropages typicus is easily distinguished from its other behaviors as it involves a strong and directed acceleration towards the prey. All recorded attacks were considered. The reaction distance of $C$. typicus $\left(R_{\mathrm{Ce}}\right)$ was estimated as the shortest distance between the body of the $C$. typicus and the nauplius immediately prior to an attack. The attack velocities were calculated considering the first 0.06 to $0.10 \mathrm{~s}$ of the event. Reaction distances and escape velocities were determined for Temora longicornis and Acartia tonsa nauplii trying to escape attacking $C$. typicus.

\section{RESULTS}

\section{Pipette experiments}

Data from trials with similar stage distributions were pooled according to Table 1 . Starting positions of the escape jumps were distributed around the pipette, with a tendency towards more points at the side of the pipette (Fig. 3). This pattern is consistent with an expected random distribution with probabilities associated with the geometry of the set-up.

Temora longicornis nauplii required stronger hydrodynamic signals for eliciting escape responses than the copepodids (Fig. 2). Mean critical fluid deformation rates ranged between 2.78 and $3.96 \mathrm{~s}^{-1}$ for the nauplius stages, and between 0.73 and $0.80 \mathrm{~s}^{-1}$ for the copepo-

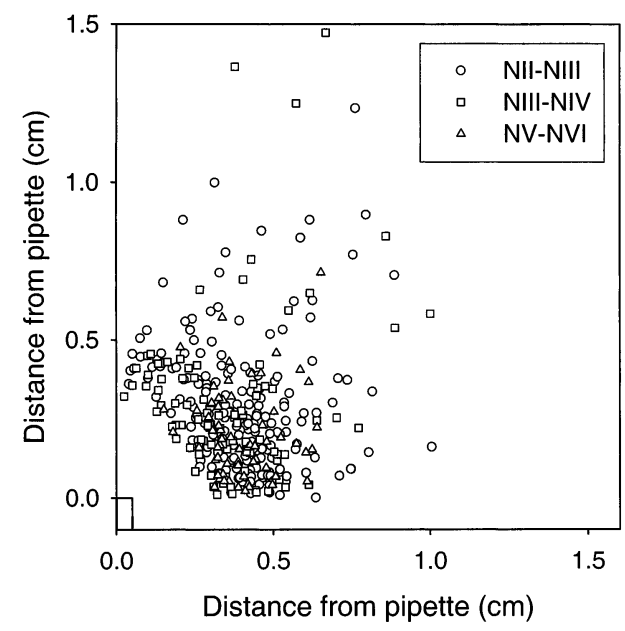

Fig. 3. Temora longicornis. Start points of escape jumps. Data are rotated onto a $90^{\circ} 2 \mathrm{D}$ front-view representation of the pipette set-up. The center of the pipette tip is at $(0,0)$ 
Table 3. Temora longicornis. Critical deformation rates $\left(\Delta^{*}\right)$ and threshold signal strengths due to critical deformation $\left(s_{\Delta^{*}}\right)$. Data are geometric means with confidence limits in parentheses. Data are from pipette experiments

\begin{tabular}{|lccc|}
\hline $\begin{array}{l}\text { Group name } \\
\text { (Pipette) }\end{array}$ & $\begin{array}{c}\Delta^{*} \\
\left(\mathrm{~s}^{-1}\right)\end{array}$ & $\begin{array}{c}S_{\Delta^{*}} \\
\left(\mathrm{~cm} \mathrm{~s}^{-1}\right)\end{array}$ & $\begin{array}{c}\text { Length } \pm \text { SD } \\
(\mu \mathrm{m})\end{array}$ \\
\hline NII-NIII (Pip 1-4) & $2.78(2.45 ; 3.15)$ & $0.024(0.027 ; 0.021)$ & $169 \pm 27$ \\
NIII-NIV (Pip 5) & $3.25(2.56 ; 4.13)$ & $0.039(0.049 ; 0.030)$ & $237 \pm 27$ \\
NV-NVI (Pip 6-7) & $3.96(3.31 ; 4.73)$ & $0.059(0.070 ; 0.049)$ & $295 \pm 43$ \\
CI-CII (Pip 8-9) & $0.73(0.56 ; 0.96)$ & $0.012(0.016 ; 0.010)$ & $341 \pm 21$ \\
CIII-CIV (Pip 10-11) & $0.81(0.52 ; 1.27)$ & $0.019(0.031 ; 0.012)$ & $486 \pm 91$ \\
& & & \\
\hline
\end{tabular}

vented a division into appropriate groups with regards to the flow line angle $(\alpha)$ and thus the attempted analysis was not pursued.

\section{Predation experiments}

Prey concentration had no effect on the error associated with pipetting and sieving nauplii, and with 1 exception, there was no difference in error between experiments. Therefore, the did stages (Fig. 2, Table 3). Threshold signal strengths increased linearly with body length in the nauplii stages, but dropped significantly in the copepodids (Table 3). Escape velocities generally increased with size (Fig. 4).

The observed jump direction relative to the horizontal appeared non-random for nauplii and copepodids (Fig. 5) and differed from a uniform distribution between $-90^{\circ}$ and $+90^{\circ}$ for both nauplii (G-test, p < $0.001)$ and copepodids $(0.01>\mathrm{p}>0.005)$. On average, nauplii jumped slightly upwards $\left(11.7 \pm 37.8^{\circ}\right)$, while copepodid stages jumped more horizontally $(-2.0 \pm$ $42.0^{\circ}$ ) (Fig. 5). For nauplii the observed distribution of jump angles relative to the flow line differed from the expected distribution for all 3 groups of $\alpha(p<0.01)$ (Fig. 6). Thus, the escape jump angles resulted from a compromise between orienting relative to gravity and relative to the flow. The nauplii generally oriented away from the flow with mean jumping directions relative to the flow lines of $71.5 \pm 40.8^{\circ}$ for $\alpha_{0-30^{\circ}}, 71.3 \pm$ $43.5^{\circ}$ for $\alpha_{30-60^{\circ}}$ and $73.1 \pm 46.0^{\circ}$ for $\alpha_{60-90^{\circ}}$. For copepodids, the lower number of observations (Table 1) pre-

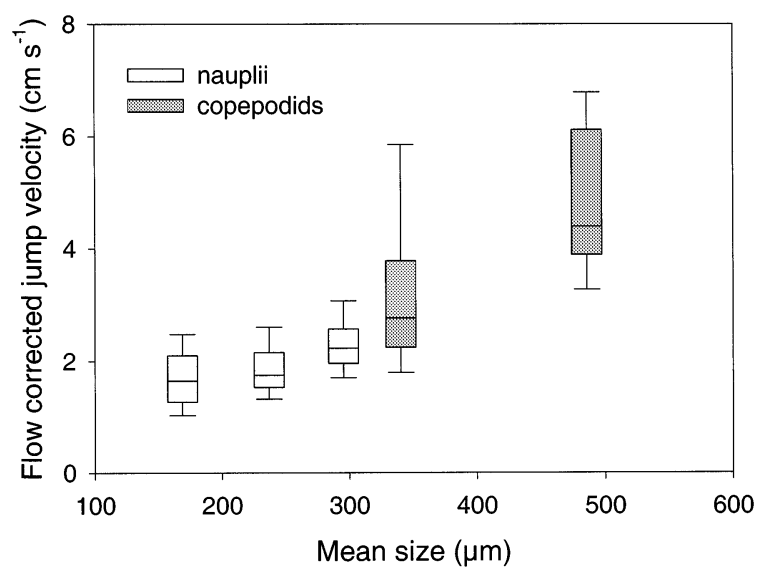

Fig. 4. Temora longicornis escape velocities. Boxes indicate the 25 to 75 percentiles, lines the median, and whiskers the 10 and 90 percentiles. Data are from pipette experiments and grouped according to Table 1 overall mean error was used in calculations of ingestion and clearance rates. Mean errors were -0.28 and -0.38 nauplii bottle ${ }^{-1}$ for Temora longicornis and Acartia tonsa respectively. One experiment (Single/mix 1) was excluded and corrected separately because the error for A. tonsa was larger on this occasion.

Ingestion rates of Centropages typicus increased linearly over the entire range of prey concentrations
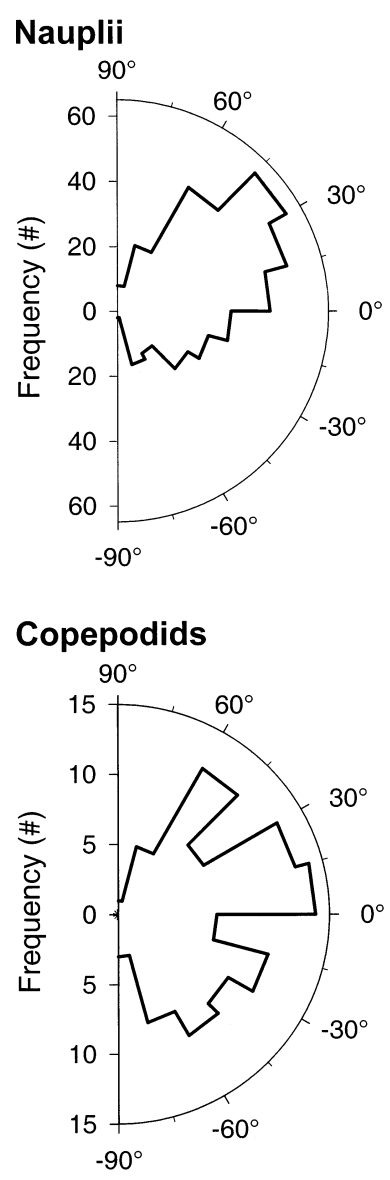

Fig. 5. Temora longicornis. Escape jump angles relative to the horizontal for nauplii and copepodids. Positive angles correspond to jumping upwards and negative angles to jumping downwards. Data are from pipette experiments 
examined for both of the prey species (Fig. 7). In the single-mix species experiments (Fig. 8), clearance rates differed between the 2 prey species $(p<0.001)$, and similar results were obtained in both mixed and single species treatments ( $p=0.863$ ) (Fig. 8). C. typicus cleared Temora longicornis nauplii $\left(442 \pm 125 \mathrm{ml}^{-1} \mathrm{~d}^{-1}\right)$ 3 times faster than it cleared Acartia tonsa nauplii $\left(146 \pm 35 \mathrm{ml}^{-1} \mathrm{~d}^{-1}\right)$.

\section{Filming of behavior}

\section{General behavior}

The motility behavior differed between the 2 prey species when considering general swimming pattern, velocities and time budgets. Temora longicornis nauplii swim in straight patterns or in smooth loops, with a strong horizontal component (Fig. 9). While periods of sinking frequently interrupt the gliding path, T. longicornis nauplii only rarely exhibit spontaneous (non-escape) jumps (Table 4). The motility of Acartia tonsa nauplii, on the other hand, is dominated by jumping if considering the distance moved, and sinking if considering the time spent (Table 4, Fig. 9). Seen in 2 dimensions, the sink-jump motility style results in a zigzag pattern (Fig. 9).

\section{Attack-escape}

Centropages typicus detected the Acartia tonsa nauplii at a greater distance away than it detected Temora longicornis (Table 5) ( $t$-test, non-equal variances assumed, $\mathrm{p}=0.002$ ). However, the velocities with which $C$. typicus attacked the 2 prey species were similar ( $t$-test, equal variances assumed, $\mathrm{p}=0.368)$. $A$. tonsa detected the predator at a much greater distance away than T. longicornis did (Table 5), and A. tonsa always initiated the escape jump before the attacking predator reached it. T. longicornis only did this in 1 case. The other $T$. longicornis nauplii reacted only upon direct contact with the C. typicus, after which they initiated escape and managed to flee the predator. The T. longicornis were able to escape longer than $A$. tonsa ( $t$-test, equal variances assumed, $\mathrm{p}=0.016$ ) (Table 5). For both species, the length of the escape jump was an order of magnitude higher than the length of the spontaneous jumps. The 2 prey species exhibited similar escape velocities ( $t$-test, equal variances assumed, $\mathrm{p}=0.472$ ) (Table 5). In addition, both prey escaped with velocities similar to $C$. typicus attack velocity (Table 5).
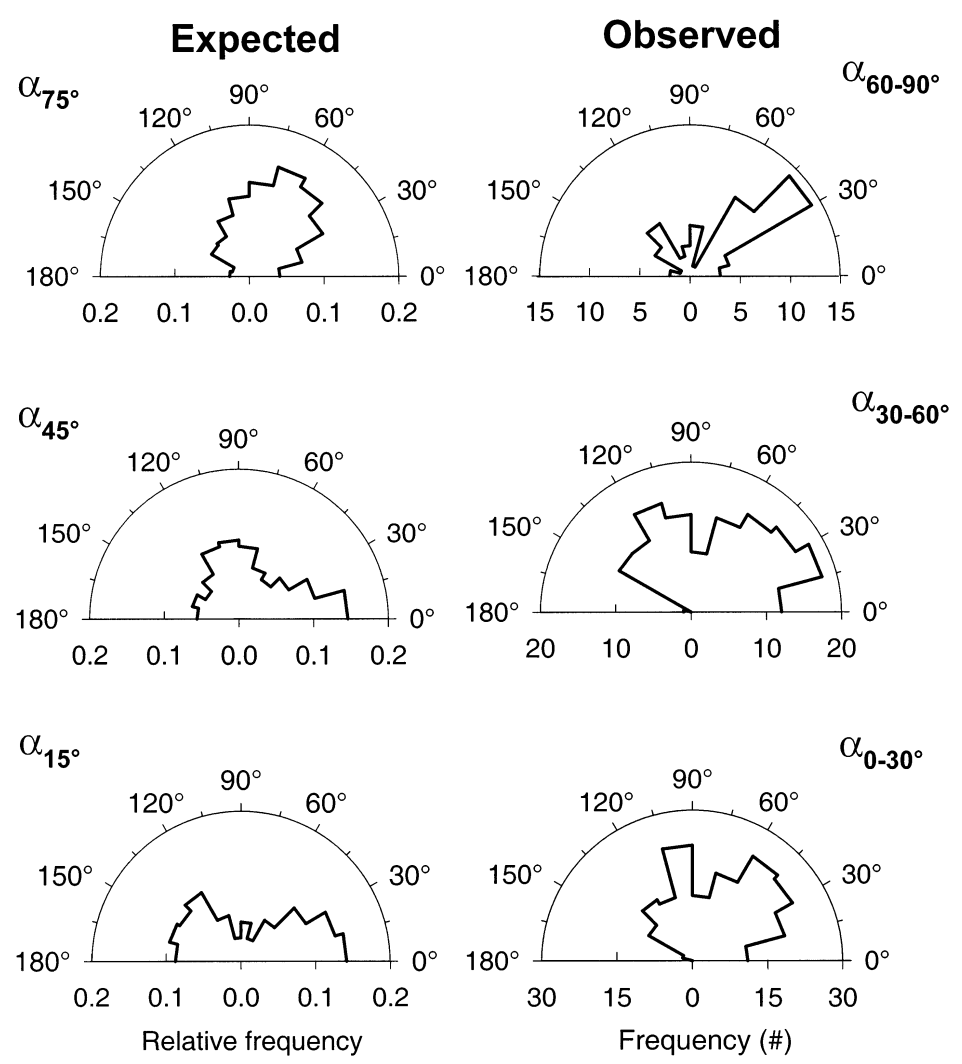

Fig. 6. Temora longicornis. Expected and observed jump angles relative to the flow line. Expected jump angles at flow lines of representative angles of $\alpha$ were obtained from the distributions in Fig. 5. Because the expected jump angles change with $\alpha$, the observed data were grouped into $\alpha_{0-30^{\circ}}, \alpha_{30-60^{\circ}}$ and $\alpha_{60-90^{\circ}}$. Data are from pipette experiments

\section{DISCUSSION}

\section{Prey behavior and components of encounter rates}

Predator-prey encounter rates are proportional to the velocity difference between predator and prey and the square of the predator's detection distance $\left(R^{2}\right)$ (Kiørboe \& Saiz 1995). It has been argued (e.g., Wong et al. 1986) that prey cannot alter encounter rates significantly because changes in velocity of 'slow' prey only slightly affect the velocity difference. However, $R$ depends on the hydrodynamic signal generated by the prey, and thus both on prey size and prey velocity (Tiselius \& Jonsson 1990, Kiørboe \& Visser 1999, Svensen \& Kiørboe 2000). Zooplankton prey can therefore limit both detection and encounter with predators by reducing their motility (Kerfoot 1978, Meng \& Orsi 1991, Tiselius et al. 1997).

Acartia tonsa and Temora longicornis nauplii exhibited strong differences in motility, both regarding swimming patterns (Fig. 9), and the time spent in the 


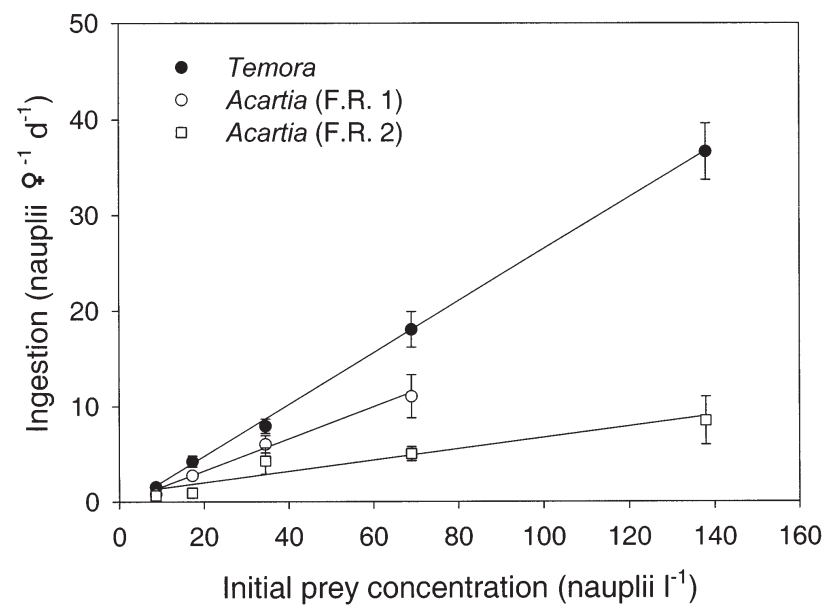

Fig. 7. Centropages typicus functional response on nauplii of Acartia tonsa and Temora longicornis. Each point is the mean of 5 replicates \pm SE. Regression lines (based on the individual samples) are for $T$. longicornis: $y=0.271 x-0.639\left(\mathrm{r}^{2}=0.95\right)$; A. tonsa FR 1: $y=0.168 x-0.139\left(\mathrm{r}^{2}=0.71\right)$; and A. tonsa FR 2: $y=0.059 x+0.817\left(\mathrm{r}^{2}=0.49\right)$. See Table 2 for prey size and stage distributions

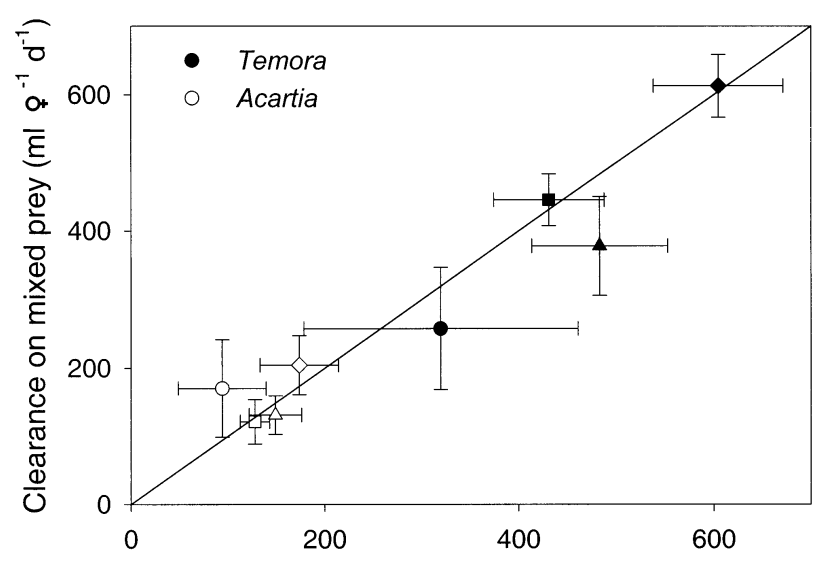

Clearance on single prey $\left(\mathrm{ml}^{-1} \mathrm{~d}^{-1}\right)$

Fig. 8. Centropages typicus feeding on nauplii of Acartia tonsa and Temora longicornis. Single-mixed species predation experiments. Data points are mean values of 5 to 7 replicates \pm SE. The reference line is $x=y$. Fill colors indicate the prey species while the symbol shapes indicate the experiment (๑० Single/mix 1; $\square$ Single/mix 2; $\Delta \triangle$ Single/mix 3; $\diamond$ Single/mix 4). The C. typicus were in bad shape in Expt 1. See Table 2 for prey size and stage distributions

various behaviors (Table 4). By spending more time in a low velocity type of behavior, such as sinking, a prey may reduce the hydrodynamic signal that can be perceived by a predator, and thus limit the time exposed to predators. Tiselius et al. (1997) found that, although Acartia clausi allocated only $7 \%$ of its time to jumping, this time corresponded to $>80 \%$ of the encounters with the predatory Paraeuchaeta norvegica.

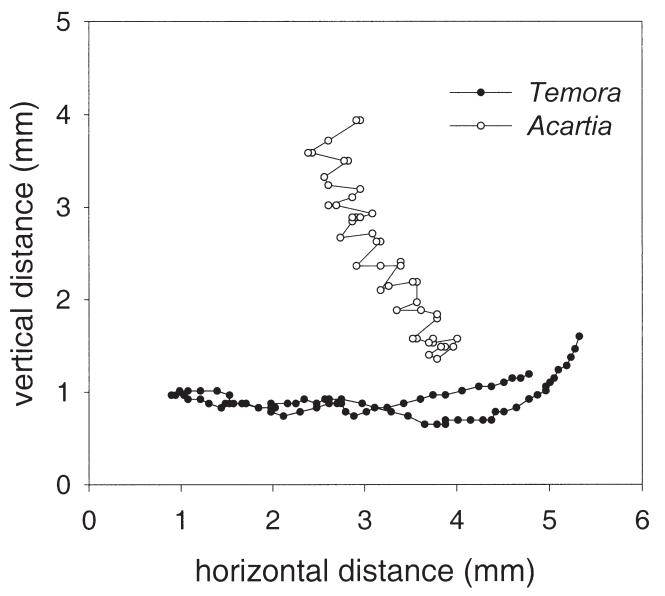

Fig. 9. Acartia tonsa and Temora longicornis nauplii. Representative 2D swim paths. Each track corresponds to 400 frames (= $16 \mathrm{~s})$. Only every fifth frame is shown in the plot

The theoretical reaction distance $(R)$ can be estimated for a sinking or jumping prey using a creeping flow model, while a swimming prey may be better modeled as a dipole (Svensen \& Kiørboe 2000). In the first case $R$ scales with $\frac{a V}{u^{*}}$ and in the second case $R$ scales with $a \sqrt{\frac{v}{u^{*}}}$, where $u^{*}$ is the threshold signal strength for prey detection, $a$ is the prey radius, and $V$ is prey velocity. Because no independent estimate of $u^{*}$ exists for Centropages typicus, the observed $R_{\mathrm{Ce}}$ (Table 5) cannot be compared to model predictions. An estimation of $u^{*}$ using the observed maximum $R_{\mathrm{Ce}}$ values, prey sizes and velocities for the dominating signal generating behaviors (Tables 4 \& 5) in the models of Svensen \& Kiørboe (2000) yields $u^{*}$ values of 0.02 to $0.3 \mathrm{~cm} \mathrm{~s}^{-1}$, depending on whether considering jumping Acartia tonsa or swimming Temora longicornis nauplii. Although it is unclear how to weigh the relative time that prey spend in different behaviors (Table 4), and although uncertainties concerning how $R_{\text {Ce }}$ scales to the different behaviors remain, the 6 -fold difference between the observed $R_{\mathrm{Ce}}$ on $A$. tonsa and T. longicornis nauplii (Table 5) likely reflects the differences in prey motility behavior (Table 4, Fig. 9).

In the simplest fashion possible, for relative purposes only, the volume encounter rate $\left(E, \mathrm{ml}^{-1} \mathrm{~d}^{-1}\right)$ for Centropages typicus detecting nauplii prey is:

$$
E=\pi\left(R_{\text {Ce }}+a_{\text {prey }}\right)^{2} \Delta v \times 3600 \times 24
$$

where $\Delta v$ is the relative velocity $\left(\mathrm{cm} \mathrm{s}^{-1}\right)$ between predator and prey, here simplified to $v_{\mathrm{Ce}}$, and $a_{\text {prey }}$ is the radius of the prey. Using sizes and $R_{\mathrm{Ce}}$ values from Table 5 (adjusted with half the body width of $C$. typicus because the equation assumes $R_{\mathrm{Ce}}$ to be measured from the center of the reaction sphere) and $v_{\mathrm{Ce}}=0.3 \mathrm{~cm}$ 
Table 4. Temora longicornis and Acartia tonsa. Velocities ( $v$ ) and time budgets of spontaneous prey behavior. Data are means $\pm \mathrm{SD}$. Body lengths are $298 \pm 38 \mu \mathrm{m}$ for T. longicornis and $198 \pm 9.8 \mu \mathrm{m}$ for A. tonsa

\begin{tabular}{|c|c|c|c|c|c|c|}
\hline & $\begin{array}{c}V \\
\left(\mathrm{~mm} \mathrm{~s}^{-1}\right)\end{array}$ & $\begin{array}{c}\text { nora longicol } \\
\text { Time spent } \\
(\%)\end{array}$ & $\begin{array}{l}\text { Frequency } \\
\left(\text { no. } \mathrm{s}^{-1}\right)\end{array}$ & $\begin{array}{c}V \\
\left(\mathrm{~mm} \mathrm{~s}^{-1}\right)\end{array}$ & $\begin{array}{c}\text { Acartia tonsa } \\
\text { Time spent } \\
(\%)\end{array}$ & $\begin{array}{c}\text { Frequency } \\
\left(\text { no. } \mathrm{s}^{-1}\right)\end{array}$ \\
\hline Jump & $9.1 \pm 4.83$ & $0.7 \pm 1.0$ & $0.3 \pm 0.49$ & $5.8 \pm 1.78$ & $12.3 \pm 4.18$ & $3.1 \pm 1.05$ \\
\hline Swim & $0.82 \pm 0.18$ & $58.9 \pm 29.3$ & - & - & - & - \\
\hline Sink & $0.17 \pm 0.24$ & $40.4 \pm 29.6$ & - & $0.09 \pm 0.18$ & $87.7 \pm 4.18$ & - \\
\hline
\end{tabular}

Table 5. Behavior and detection distances $(R)$ of free swimming Centropages typicus and nauplii prey during attacks

\begin{tabular}{|c|c|c|}
\hline & $\begin{array}{l}\text { Temora longicornis } \\
\qquad(\mathrm{n}=4) \\
\text { Mean } \pm \mathrm{SD}\end{array}$ & $\begin{array}{c}\text { Acartia tonsa } \\
(\mathrm{n}=11) \\
\text { Mean } \pm \mathrm{SD}\end{array}$ \\
\hline \multicolumn{3}{|l|}{ Prey } \\
\hline$R_{\text {Nauplius }}(\mathrm{mm})$ & $0.11^{\mathrm{a}}$ & $0.81 \pm 0.42$ \\
\hline Jump length (mm) & $8.62 \pm 4.66$ & $3.46 \pm 2.46$ \\
\hline Jump speed (mm s${ }^{-1}$ ) & $37.0 \pm 11.1$ & $44.4 \pm 18.8$ \\
\hline Body length $(\mu \mathrm{m})$ & $298 \pm 38$ & $198 \pm 9.8$ \\
\hline \multicolumn{3}{|l|}{ Predator } \\
\hline$R_{\mathrm{Ce}}(\mathrm{mm})$ & $0.34 \pm 0.18$ & $2.37 \pm 1.46$ \\
\hline Attack speed $\left(\mathrm{mm} \mathrm{s}^{-1}\right)$ & $48.3 \pm 16.0$ & $40.3 \pm 14.6$ \\
\hline
\end{tabular}

$\mathrm{s}^{-1}$ for a swimming C. typicus (Caparroy et al. 1998), this estimation yields a 10 -fold difference in encounter rates. The volume encounter rate is $\sim 500 \mathrm{ml} \mathrm{d}^{-1}$ and $\sim 5000 \mathrm{ml} \mathrm{d}^{-1}$ on nauplii of Temora longicornis and Acartia tonsa, respectively.

In contrast to the encounter rate predictions, clearance rates of Centropages typicus were generally 3 times higher on Temora longicornis than on Acartia tonsa ( 450 and $\sim 150 \mathrm{ml}^{-1} \mathrm{~d}^{-1}$, respectively) (Fig. 8). While the theoretical encounter estimate reasonably agreed with the observed clearance on T. longicornis, the observed clearance on $A$. tonsa nauplii was much less than the predicted encounter. This implies that some factor related to prey escape behavior is important in explaining the differences in predation rates on the 2 prey species. The clearance rate of $C$. typicus feeding on $A$. tonsa obtained here is comparable to that of Centropages hamatus feeding on predominantly Acartia spp. nauplii, $100 \mathrm{ml}$ ind.$^{-1} \mathrm{~d}^{-1}$ (calculated from Conley \& Turner 1985).

By combining the observed clearance rates $(F)$ with the theoretical encounter rates $(E)$ one can estimate the probability of prey escape success $\left(S_{\text {prey }}\right)$ as

$$
F=E\left(1-S_{\text {prey }}\right)
$$

This implies that the escape success of Acartia tonsa is ca 10-fold that of Temora longicornis ( 98 and 10\% respectively). Several observations of the perception and escape behavior of the 2 prey species support this notion.

\section{Components of prey escape success}

Temora longicornis nauplii require higher deformation rates than Acartia tonsa nauplii do to elicit an escape response (Fig. 2). This implies that $A$. tonsa may respond to a potential predator at a greater distance away than a T. longicornis could. The observed prey response distances to approaching Centropages typicus are consistent with the different sensitivities to hydrodynamic signals recorded in siphon experiments (Table 5, Fig. 2). In fact, 3 out of 4 attacked T. longicornis only escaped after direct contact with the C. typicus, while $A$. tonsa always perceived the predator at a distance (Table 5). Because the Reynolds number $(R e)$ during attacks is high $(>10)$, and because the attack situation involves a strong acceleration, the theoretical distance at which a nauplius can detect the predator is difficult to model (cf. Kiørboe \& Visser 1999 for a low Re situation).

The distribution of jump angles of the Temora longicornis nauplii reflected a compromise between orienting the escapes with respect to gravity and flow direction (Figs. $5 \& 6$ ). In its extension, this suggests that a nauplius prey may somehow be able to orient its escape jump relative to the signal from a predator. The ability to sense direction and directing the escape accordingly may depend on the initial body orientation of the prey. Acartia hudsonica nauplii were largely unable to modify their escape direction measured relative to the longitudinal axis of their own bodies (Fields \& Yen 1997b). In the feeding current of a tethered Euchaeta rimana, the $A$. hudsonica nauplii were rotated by the vorticity in the predator's flow field, which thus influenced the final direction of the escape jumps (Fields \& Yen 1997b). The value of non-random directionality of escape likely varies with the feeding strategy of the predator. For prey success, the relative im- 
portance of directing jumps may be inversely proportional to the prey's sensitivity to hydrodynamic signals.

Paffenhöfer \& Knowles (1980) suggested that once a nauplius is within a few $\mathrm{mm}$ of a copepod predator, there is little chance of prey escape. However, when attacked, both Acartia tonsa and Temora longicornis nauplii jumped out of the detection range of the predator (i.e., longer than $R_{\mathrm{Ce}}$ ) and both escaped with velocities similar to the attack velocity of Centropages typicus (Table 5). Two implications arise from the latter observation. First, any difference in prey escape success here is unrelated to escape velocity, and second, given sufficient perceptive capabilities nauplii would often escape this type of predator. The escape velocities observed both in the encounters (Table 5) and in the pipette set-up (Fig. 4) are similar to those previously reported for nauplii (Tiselius \& Jonsson 1990).

I observed other qualitative differences related to prey behavior during the encounters. When attacking Temora longicornis, Centropages typicus always hit the swimming prey. In contrast, $C$. typicus responded to the jumping Acartia tonsa by attacking the spot where the prey had just left, thus missing the prey. Although the behavior of $A$. tonsa clearly alerts C. typicus as demonstrated by the high $R_{\text {Ce }}$ (Table 5), the behavior of the prey apparently confuses this predator. This may suggest that the high encounter rate on $A$. tonsa does not represent a true increase in predation risk for this prey.

The combination of observations of predator and prey encounters (Table 5) and the data on prey perception (Fig. 2) implies that the poorer predator detection of Temora longicornis is responsible for the high clearance rates found on this species. Similarly, the key to the relative success of Acartia tonsa in this study lies in the low $\Delta^{*}$ to which it responds.

\section{Prey strategies}

A difference in behavior may reflect differences in strategies concerning optimizing feeding (Landry \& Fagerness 1988, Lima \& Dill 1990, Tiselius \& Jonsson 1990, Kiørboe et al. 1996) and predator avoidance (Sih 1980, Ohman 1988, Lima \& Dill 1990). Although both are important for the success of a species, failure to escape predators obviously has more detrimental consequences for the lifetime fitness (Sih 1980, Lima \& Dill 1990). Because hydrodynamic signals are generated by all aspects of a copepod's behavior, including feeding and mating, there is an inherent dilemma associated with the behavior of an individual (Paffenhöfer et al. 1996, Tiselius et al. 1997).

Seen from a predator avoidance perspective, the behavior of the 2 prey species used here limits preda- tion rates through different steps in the predation chain. While the low profile motility behavior of Temora longicornis appears to reduce encounter rates, its post encounter (i.e., escape) behaviors are less effective. The behavior of Acartia tonsa, on the other hand, acts predominantly at the post-encounter stage. Thus, the sensitivity of $A$. tonsa to hydrodynamic signals (i.e., low $\Delta^{*}$ ) effectively compensates for the high predator encounter rate generated by the motility of $A$. tonsa. Different species may be expected to employ different strategies, as the behavior of any organism needs to be flexible enough to account for short-term changes in predation risk as well as to optimize longterm fitness (Sih 1980, Lima \& Dill 1990). Hence, the range of motility behavior found in copepods (Landry \& Fagerness 1988, Tiselius \& Jonsson 1990, van Duren \& Videler 1995, Paffenhöfer et al. 1996) and the different strategies observed here are not surprising.

Differences in copepod predation rates are usually explained by focusing on the predator, often in terms of more or less active selection of prey particles. Here, in contrast, the differences in observed predation rates on the 2 nauplii prey clearly result from prey behavior. Thus, this study illustrates an example of how prey behavior may significantly influence both encounter and post-encounter components of the predation process.

Acknowledgements. I benefited from the advice and encouragement of Thomas Kiørboe and Peter Tiselius, as well as from their comments on previous drafts of this paper. The predation experiments were carried out in September 1999 at Kristineberg Marine Research Station, Sweden, where Pia Petterson assisted in the laboratory. Andy Visser helped with the mathematics associated with the pipette experiments. Thanks are also due to students and staff at the Danish Institute for Fisheries Research and KMRS for help and discussions. Comments from 3 anonymous referees improved the paper. This study was financed by a EU-TMR Marie Curie PhD Fellowship (ERBFMBICT 972833) to J.T. and a grant (No. 9801391) from The Danish Natural Sciences Research Council to Thomas Kiørboe.

\section{LITERATURE CITED}

Buskey EJ (1994) Factors affecting feeding selectivity of visual predators on the copepod Acartia tonsa: locomotion, visibility, and escape responses. Hydrobiologia 292/293: $447-453$

Caparroy P, Pérez MT, Carlotti F (1998) Feeding behavior of Centropages typicus in calm and turbulent conditions. Mar Ecol Prog Ser 168:109-118

Conley WJ, Turner JT (1985) Omnivory by the coastal marine copepods Centropages hamatus and Labidocera aestiva. Mar Ecol Prog Ser 21:113-120

Fields DM, Yen J (1997a) The escape behavior of marine copepods in response to a quantifiable fluid mechanical disturbance. J Plankton Res 19:1289-1304

Fields DM, Yen J (1997b) Implications of the feeding current 
structure of Euchaeta rimana, a carnivourous pelagic copepod on the spatial orientation of their prey. J Plankton Res 19:79-95

Haury LR, Kenyon DE, Brooks JR (1980) Experimental evaluation of the avoidance reaction of Calanus finmarchius. J Plankton Res 2:187-202

Heuch PA, Karlsen HE (1997) Detection of infrasonic water oscillations by copepodids of Lepeophtheirus salmonis (Copepoda: Caligida). J Plankton Res 19:735-747

Jakobsen HH (2001) Escape response of planktonic protists to fluid mechanical signals. Mar Ecol Prog Ser (in press)

Kerfoot WC (1978) Combat between predatory copepods and their prey: Cyclops, Epischura and Bomina. Limnol Oceanogr 23:1089-1102

Kiørboe T, Saiz E (1995) Planktivorous feeding in calm and turbulent environments, with emphasis on copepods. Mar Ecol Prog Ser 122:135-145

Kiørboe T, Visser A (1999) Predator and prey perception in copepods due to hydromechanical signals. Mar Ecol Prog Ser 179:81-95

Kiørboe T, Saiz E, Viitasalo M (1996) Prey switching behaviour in the planktonic copepod Acartia tonsa. Mar Ecol Prog Ser 143:65-75

Kiørboe T, Saiz E, Visser A (1999) Hydrodynamic signal perception in the copepod Acartia tonsa. Mar Ecol Prog Ser 179:97-111

Landry MR (1978) Predatory feeding behavior of a marine copepod, Labidocera trispinosa. Limnol Oceanogr 23: 1103-1113

Landry MR (1980) Detection of prey by Calanus pacificus: implications of the first antennae. Limnol Oceanogr 25: 545-549

Landry MR, Fagerness VL (1988) Behavioral and morphological influences on predatory interactions among marine copepods. Bull Mar Sci 43:509-529

Légier-Visser MF, Mitchell JG, Okubo A, Fuhrman JA (1986) Mechanoreception in calanoid copepods. Mar Biol 90: 529-535

Lima SL, Dill LM (1990) Behavioral decision made under the risk of predation: a review and prospectus. Can J Zool 68: 619-640

Meng L, Orsi JJ (1991) Selective predation by larval striped bass on native and introduced copepods. Trans Am Fish Soc 120:187-192

Ohman MD (1988) Behavioral responses of zooplankton to predation. Bull Mar Sci 43:530-550

Paffenhöfer GA, Knowles SC (1980) Omnivorousness in marine planktonic copepods. J Plankton Res 2:355-365

Paffenhöfer GA, Strickler JR, Lewis KD, Richman S (1996)

Editorial responsibility: Otto Kinne (Editor), Oldendorf/Luhe, Germany
Motion behavior of nauplii and early copepodid stages of marine planktonic copepods. J Plankton Res 18: 1699-1715

Sih A (1980) Optimal behavior: can foragers balance two conflicting demands? Science 210:1041-1043

Singarajah KV (1969) Escape reactions of zooplankton: the avoidance of a pursuing siphon tube. J Exp Mar Biol Ecol 3:171-178

Sokal RR, Rohlf FJ (1995) Biometry: the principles and practice of statistics in biological research, 3rd edn. WH Freeman \& Co, New York

Støttrup JG, Richardson K, Kirkegaard E, Pihl NJ (1986) The cultivation of Acartia tonsa Dana for use as live food source for marine fish larvae. Aquaculture 52:87-96

Svensen C, Kiørboe T (2000) Remote prey detection in Oithona similis: hydromechanical versus chemical cues. J Plankton Res 22:1155-1166

Tiselius P, Jonsson PR (1990) Foraging behaviour of six calanoid copepods: observations and hydrodynamic analysis. Mar Ecol Prog Ser 66:23-33

Tiselius P, Jonsson PR, Kaartvedt S, Olsen EM, Jørstad T (1997) Effects of copepod foraging behavior on predation risk: An experimental study of the predatory copepod Pareuchaeta norvegica feeding on Acartia clausi and A. tonsa (Copepoda). Limnol Oceanogr 42(1):164-170

van Duren LA, Videler JJ (1995) Swimming behaviour of developmental stages of the calanoid copepod Temora longicornis at different food concentrations. Mar Ecol Prog Ser 126:153-161

Viitasalo M, Rautio M (1998) Zooplanktivory by Praunus flexuosus (Crustacea: Mysidacea): functional responses and prey selection in relation to prey escape responses. Mar Ecol Prog Ser 174:77-87

Viitasalo M, Kiørboe T, Flinkman J, Pedersen LW, Visser AW (1998) Predation vulnerability of planktonic copepods: consequences of predator foraging strategies and prey sensory abilities. Mar Ecol Prog Ser 175:129-142

Wong CK (1996) Response of copepods to hydromechanical stimuli. Crustaceana 69:853-859

Wong CK, Ramcharan CW, Sprules WG (1986) Behavioral responses of a herbivorous calanoid copepod to the presence of other zooplankton. Can J Zool 64:1422-1425

Yen J, Fields DM (1992) Escape responses of Acartia hudsonica (Copepoda) nauplii from the flow field of Temora longicornis (Copepoda). Arch Hydrobiol Beih Ergebn Limnol 36:123-134

Yen J, Lenz PH, Gassie DV, Hartline DK (1992) Mechanoreception in marine copepods: electrophysiological studies on the first antennae. J Plankton Res 14:459-512

Submitted: June 23, 2000; Accepted: September 6, 2000 Proofs received from author(s): March 16, 2001 